Article

\title{
The Development of Philosophy and Its Fundamental Informational Turn
}

\section{Kun Wu}

International Center for the Philosophy of Information, Xi'an Jiaotong University, Xianning West Road 28, Xi'an 710049, China; E-Mail: wukun@mail.xjtu.edu.cn; Fax: +86-29-8266-8281

Academic Editors: Mark Burgin and Wolfgang Hofkirchner

Received: 8 September 2015 / Accepted: 16 October 2015 / Published: 21 October 2015

\begin{abstract}
Through the rescientification of philosophy and the philosophization of science, an entirely new concept of science and philosophy as part of general human knowledge is developing. In this concept, science and philosophy become intrinsically integrated and unified, forming dynamic feedback-loops which lead to further mutual transformation and integration. This development is taking place in the face of two kinds of dogmatism: one is naturalistic dogmatism, the other the dogmatism of consciousness philosophy. These two kinds of dogmatism are an inevitable consequence of the method of segmentation of the field of existence in traditional philosophy namely: existence $=$ matter + Spirit (mind). The development of the Science and Philosophy of Information reveals a world of information-by-itself lying between the worlds of matter and Sprit, and re-interprets the essence of the Spiritual world in the sense of prior information activities. Accordingly, we can describe the movements from matter to Spirit, and from Spirit to matter in these activities as processes, eliminating their dualistic separation, and achieve an informational turn in philosophy, the first truly fundamental one.
\end{abstract}

Keywords: development; dogmatism; field of existence; fundamental turn: information; philosophy; science; spirit

\section{Foreword}

Two introductory comments are necessary for the comprehension of this article, one pertaining to the term "spirit" and one regarding the references cited. 
There are two major meanings of the term "spirit": that of an "objective" existing spirit which refers to God or an Absolute idea and a personal spirit of human beings, corresponding to the terms "mind" or "consciousness" in Western thought. In modern Chinese philosophical terminology, the term "spirit" can be used in both those situations. Both Chinese and Western materialists, of whom I am one, do not accept the existence of an objective spirit as defined. The so-called objective spirit, which does not exist in the real objective world, is only a creation of personal spirit. It is, however, unnecessary to distinguish the two concepts of spirit in Chinese, and my use of the terms spirit and spiritual in this paper is exclusively in the personal sense. They have been capitalized to insure that this usage is kept in mind by the reader. Spirit has not been translated as "mind" in order to mark that the concept remains open to alternative meanings.

The reader will find that essentially all of the references are to articles in Chinese, primarily authored by myself. Although unusual, this is intentional, in that this particular article is intended to report my own independent research achievements. In the future, the relation of my work to that of others can be established and indeed in part already has been in other articles published in English since 2011.

\section{Introduction: The Limitations of Contemporary Western Philosophy}

Although there are many different schools of philosophy in the West, they all share a common weakness. According to the standard academic argument, the mainstream of development of contemporary Western philosophy experienced a transformation from ontology to epistemology and then to linguistics and phenomenology. The essence of this conversion was an increasingly narrow focus on internal subject matter as the main content of philosophical research, leading to the increasing separation of philosophy and science. Research into ontology was rejected; philosophical research tasks were restricted to the cognitive field, supplemented by psychological and linguistic analysis, involving narrow structural aspects of intentional activity. Such a direction of study made the development of Western philosophy increasingly one-sided, simplistic, and narrow and eventually led to an embarrassing isolation increasingly far from science and in conflict with it.

Such a path of development of Western philosophy made it into an increasingly weak discipline, going down a path of no return. One obvious fact is that, due to the narrowing of its field of discourse, Western philosophy lost the capacity to provide a general view of the world and explain its transformation. If this situation does not change, philosophy will increasingly lose its function. Accordingly, we think it is not surprising that some Western post-modernist scholars take extreme positions, talking about deconstructing or abolishing philosophy completely.

\section{A New Path for the Development of Philosophy in Relation to Science}

In fact, in addition to the above "dead end" path, there is another path for the development of philosophy, which is to participate in the general process of general scientific development. On the one hand, rational scientific construction needs philosophical thinking and exploration, and on the other, the progress of science can pave the way for the development of philosophy [1].

Modern science, from the development of Newtonian mechanics and atomic theory, deepened and expanded the philosophical ontology of entity realism founded by ancient Greek philosophy. Subsequently, the realist energy field concepts studied by the theory of relativity, quantum mechanics 
and cosmology provide the most direct scientific basis for the foundation and development of a philosophical ontology theory. The birth and development of contemporary information science provides another scientific basis for a philosophical ontology via its dual existence and dual evolution theory of material and information put forward by the philosophy of information. In this view, the ontological domain of philosophy has not stagnated as a result of its rejection or suspension by some philosophers. Instead, the process of scientific development itself contains the metaphysics of a new philosophical ontology. Metaphysics and physics always accompany one another in the exploration and development of science.

Equally obvious is the fact that development of experimental science profoundly promotes the development of the theory of human cognition. Research in medicine, anatomy, physiology, neurophysiology, brain science, experimental psychology, etc., has led contemporary cognitive science to new insights into the origins and mechanisms of cognition, adding a new philosophical dimension to prior achievements in all forms of epistemology. Thus, Francis Bacon had criticized early any theory of cognition based on the extremes of empiricism and rationalism. He emphasized that a true philosophy should be a product of scientific experiments but in a close union with concepts of human rationality. In his critique of extreme rationalism, he also put forward a theory which stated that in the mental structure of human beings there are "Four Programs" disturbing the human mentality and hindering the development of science. The French Enlightenment thinker Julien Offroy de La Mettrie (1709-1751) used the medicinal and the bio-anatomical and physiological science of his time to interpret human feeling, thinking and other Spiritual activities from physiological characteristics, the state of the human body, and a conception of levels in the human brain. In the context of contemporary scientific development, much of the theory of epistemology is being built on the achievements of corresponding scientific developments. We can highlight genetic epistemology theory, experimental and behavioral psychology, theories of brain function and pattern recognition mechanisms, cognitive science and virtual epistemology, the information epistemology theory of the philosophy of information, and so on.

\section{The Development of Science and Philosophy through their Recursive Interaction}

A distinctive feature of all the above theories of epistemology is that they combine science and philosophy: all combine concepts of internal structure and activities of the subject and external factors, and do not seek the explanation of, for example, the mechanism of pattern recognition solely from the internal activities of the individual subject. Obviously, such a theory is a reflection of a mode of development involving the rescientification of philosophy and philosophization of science. The method used fits the main ideas of complexity provided by the theory of contemporary complex information systems, which is that of a multi-coordinated integral emergence theory (cf. paragraph 8).

The originator of the theory of the paradigm of complexity, Edgar Morin (1921-) presents a dynamic methodology, compatible with the complementarity of opposites. He thinks two basic principles constitute the complexity method: the logical duality principle and the regression loop principle. He emphasizes that "opposite principles and concepts are complementarily connected in an inseparable way". The process principle of universe creates and generates itself and includes our understanding of the principle as a "regressive loop" ([2], pp. 1-2). Morin particularly emphasizes the thought that the 
interaction between opposing factors and multiple factors are the source of complexity, and the method of description of the interaction process should be that of such regression loops.

He thinks that the method of absolute separation of opposites (diversity) was an antique principle of simplicity. He advocates in natural science and social science (Humanities) and philosophy, looking at the individual and the society and species; physics and biology and anthropology and sociology; order and disorder and organization; science and politics and ideology; the whole and the part and their interaction; science and technology and society and the state; subject and object, Spirit and matter, humanity and nature, nature and society, and so on, all areas of such opposites and multiple links, in order to establish the comprehension of regression loops of their common interaction. Morin says that the corresponding comprehensive regression loop relations reveal the infrangible complex comprehensiveness of the object itself between opposing, multiple elements. It is the dynamic, circular repeated, universal interactions that represent the general process and the specific mechanism of self-organized innovation and development. In his view, complexity is constructed by these dynamic self-organized activities of these feedback regression loops. He wrote: "Descartes established the paradigms which ruled Western thought: subject and object are separated, as are the spiritual and the material; the person and nature are opposites. If a new method can be born and grow from the complexity principle, it may also 'cause a revolution everywhere', even a revolution in the idea of revolution that has come to appear trite and insignificant, aging and reactionary" ([2], pp. 2-5).

From the complexity point of view, science and philosophy are not absolutely separated; they are prescribed by, comprised of and integrated with each other in a process of interaction. Science inheres in philosophy; philosophy inheres in science. The two form together a dynamic interactional feedback loop, the development of one always influencing the other in a mutual determination and transformation. In a 2004 article entitled "On the relationship between philosophy and science" [3], I wrote: "The unity of philosophy and science can not be simply recognized as an external connection, but should be seen as an intrinsic fusion; universal rationality and specific perception in the process of human cognition can not be completely separated, and this is the ultimate basis of the intrinsic unity of philosophy and science. The internal differences of levels and prevalence in universal reason provide the level structure of science and philosophy themselves, and their relativity. The transition from lower to higher levels of universal rationality, with the elimination of the limitations by the lower levels of the latter, and the deepening of the universal character of higher layers drives the readjustment of science to philosophy and the critique by of philosophy of science. By accepting critically this lower universal rationality, philosophies can change their old ideas, theories and systems, constructing thereby the process of their development."

The unifying relations of mutual influence, regulation, promotion and transformation in the internal integration of the interaction of science and philosophy profoundly modify the general ways and means of human knowledge development. They illustrate what I characterize as the rescientification of philosophy and philosophization of science.

\section{Two Kinds of Dogmatic Doctrine}

Husserl condemned the naturalistic attitude in general scientific research as dogmatism, and thought that the material world recognized by the naturalistic attitude was a transcendental, relative non-existence. Corresponding to this, he took the so-called "phenomenological surplus", "pure consciousness"- 
intentionality itself - as absolute unique existence, "excluding" the whole world containing all that is physical, biological, and human - ourselves [4]. He thus believed that pure consciousness was essentially independent of the entire world and natural existence, and that nature existed as constituted in normal consciousness. He emphasized that all material "data" given by the organism are non-existent, that is, would not exist without given experience [5]. Thus, Husserl established a purely absolute, independent existence of an intentional transcendental self as the basis for his whole phenomenological philosophy.

In fact, to acknowledge a transcendental self of consciousness independent of the material world has been a tradition of Western philosophy. From the "memory theory" of Plato to the "innate ideas" of Descartes, and to the "natural true idea" of Spinoza to the "natural light of reason" of Leibniz and so on, all refer to a "transcendental self- consciousness" independent of the material body. These people also found an association between transcendental self consciousness and its truth with wisdom and truth in God. Although the "God" in Husserl's interpretation of pure consciousness "had retreated" (obviously as the result of science), the tradition of a "transcendental self-consciousness" independent of matter and the human body was still preserved in Western philosophy.

However, the experiences of human cognition, perception, memory, conscious thought and objective intentional activities always occur on the base of the material brain of a human body. Further, any change of the corresponding structure and operation mode of the material brain and human body will generate a corresponding change in the activities of human consciousness. Accordingly, the existence of a transcendental conscious self independent of the material world and the body, or "pure consciousness" (intentionality itself) also has the property of transcendentalism. In this way, we are faced with two kinds of dogmatism: a naturalistic dogmatism and a dogmatism of the philosophy of consciousness.

\section{The Traditional Segmentation of the Field of Existence and the Separation of Matter and Consciousness}

In general philosophy, the first step should be to determine the different fields of existence, the relationship between each field and its ontological significance. According to the tradition of Western philosophy, the field of existence (extant domain) consists of three parts: God (God; absolute spirit; absolute idea); the material (matter); and individual consciousness (soul; Spirit). From Plato to Hegel to Descartes, including the Western Christian tradition, all aspects of this doctrine were essentially maintained intact. However, with the progress and development of human science, except in Christianity which still retained a God, in the field of general philosophy God no longer appears. What is left is only matter and consciousness.

Materialistic philosophers [4] think that the world is material-a physical world existing independently of consciousness. Consciousness is just the product of the material world developed to a certain stage, and it must be in a particular material carrier for its existence and activities, that is to say, consciousness has no uncaused property. Theories of the universe and the evolution of life, as well as the theory of human physiology, nerve and brain provide the relevant scientific evidence.

But the Western tradition of the philosophy of consciousness is the opposite: it first identified consciousness as having the property of existence independent of other things. Husserl's phenomenology, although without a concept of God, followed Descartes' principle of the separation of matter and consciousness, body and soul. In Husserl, "pure consciousness", and the existence of an 
intentional self does not need the premise and condition of God. Thus the absolute separation of matter and consciousness became set in of Western philosophy and inevitably led to the theory of the absolute separation of the subject and object in human cognition.

In the history of philosophy, ontology and epistemology are unified, although some philosophers are not willing to concede this point, especially today. Some contemporary Western philosophers, as noted above, reject or suspend ontological research and limit the scope of philosophical research to the field of human knowledge. In this view, the analysis of pure consciousness is sufficient to elucidate the occurrence and mechanism of the process of human cognition from its intentional activities, and on this basis, further elucidate all things in the world and the universe. Husserl's phenomenology was an attempt to do so: this is in essence the phenomenological theory of intentional activities and intentional structure [4].

The linguistic turn in modern Western philosophy has similar properties: philosophical questions are transformed directly into language analysis, simplifying the mechanism of cognition and reducing the world itself to a tool for human thought - the understanding and analysis of language. In the doctrine of this turn, everything in the world, complex human physical and psychological activities, and the diverse, emergent processes and mechanisms of human cognition and behavior are all invisible.

On closer inspection, in philosophical epistemology, the method of seeking to explain cognition only from the position of the activity of consciousness itself was rooted in the ontological separation of matter and consciousness. Since matter and consciousness are simple polar opposites of different kinds, the explanations of the activities and nature of consciousness cannot derive from any relation between them. Primarily, in western philosophy, the soul of God takes priority over matter, leading directly from the spirit of God to the human spirit. God is perfect spiritual existence, and people may only have some true knowledge of perfection through God's revelation. This is Plato's concept of "memories" of an immortal soul, and of Descartes, Spinoza and Leibniz's "innate ideas", as mentioned above, as well as of Hegel's relation between absolute spirit and individual consciousness. Later, with the flourishing development of Western science, references to God disappear from general science, but without a process of transition from the concept of a spirit of God to a human spirit. Due to the lack of this link, in addition to the notions of absolute separation between matter and consciousness, the problem of from where the human spirit comes leads to a further crisis of explanation. Since matter and consciousness are supposed to be separate poles, it is impossible to get from the relativity between consciousness and matter to an explanation of the process and mechanism of consciousness. This leaves as the only possibility to look within an isolated consciousness to explain the nature, process and mechanism of consciousness in general. This is the scenario that contemporary Western philosophy is facing. Kant's theory of the insurmountable gap between the subject and object, and his theory about a priori synthetic judgments, as well as Husserl's theories of intentional activity and the structure of pure consciousness, language analysis theory of consciousness in the philosophy of language, and so on, all have that feature.

To repeat, the philosophical ontology of matter and consciousness as two opposite and separated existences led directly to the understanding in philosophy of the object and the subject as two opposite and separated entities.

The elimination of the binary opposition between the subject and the object in the Western philosophy of consciousness was intentional, an attempt to use the simple sense of their subjective content as presented rather than their understanding. However, in this way, one could not explain the relationship between the objects we know, their subjective content, and external entities, nor explain the success or 
failure of external praxis. Therefore, to set up such a relationship between subject and object from internal consciousness does not really clear up the duality opposition between subject and object, but merely avoids the problems themselves.

\section{The Ontological Origin of the Crisis in Philosophy and Epistemology}

It thus looks as if the crisis of philosophy after the "withdrawal" of God is an epistemological crisis, namely, a crisis of explanation of the mechanism of human cognition. In fact, the crisis has its roots in philosophical ontology, because it is impossible to exclude the binary opposition of matter and Spirit. The "exit" of God makes the human Spirit unable to find its external reason. Therefore, philosophers took the extreme view of only seeking the basis of consciousness within consciousness, taking an attitude of rejection or suspension of ontology in philosophy.

In view of this, the key to solving the crisis of philosophy is not to give up or reject ontological research in philosophy; its tasks are precisely to reconstruct philosophical ontology theory in order to retrieve the ontological foundation of human consciousness. Here, one of the most feasible ways is to describe the relationship between matter and consciousness as a mutual interactive, transforming process. Then, in accordance with the direction of evolution of the universe, the actually occurring phenomenon of cognition is reasonably explained by the process and occurrence mechanism of consciousness.

\section{Reconceptualization of the Opposition of Matter and Consciousness: Information, Intermediaries and Processes}

To break the state of polar opposition between matter and consciousness, and to describe their relationship as a process of mutual interaction and conversion, one needs to seek a kind of bridge between them. To build this bridge, we propose first that all interactions must have mutual connectional and transitional intermediary links. One need only imagine that if an object were absolutely isolated from its exterior, without any intermediaries between them, then, the object could not interact with the environment or any other material form. Hegel elucidated the idea of a very deep theory of process, and the basic element of this theory is a conception of intermediaries, in which he gives the intermediary a very wide role and significance. In Hegel, everything is linked through an intermediary, all elements in contact with one another throughout the transformation. Modern science has proved that the four fundamental forces (gravitational, electromagnetic, weak and strong or nuclear) necessary to maintain the order of the universe operate through the transfer of corresponding intermediary particles.

The intermediaries involved in the interaction between objects are derived from the objects themselves. Accordingly, the intermediary, through its own properties and structure can characterize and show the properties, characteristics and different relations of those objects. In other words, it can become the carrier of information related to those objects. Or rather, it $i s$ the information related to those objects. Because interaction is the way things exist, and the evolution of the objects in the universe does not have its basis in time, the structures of all objects in existence are generated after a long period of evolution. This means that all objects in the world have always been informational with their information coded by their generated structures.

Our major conclusion is, therefore, that all objects, including even the entire universe have a dual existence: all of them are not only material but also informational objects. Based on the dual material 
(direct existence) and informational (indirect existence) existence of the world, we can establish a new philosophical theory of ontology - informational ontology, which is the central part of the basic theory of the philosophy of information theory I founded in 1980. According to this theory, consciousness is information (as indirect existence) too, but it is the subjective form of information, namely the world of for-itself and reproduced information. I proposed that there is an objective information world in the objective world, which I called the world of by-itself information. Thus, according to this informational ontology theory, the world (existence) is composed of two major domains of matter and information, and matter and consciousness transform one another through the intermediary of by-itself information, which links them. In this way, the relationship between matter and consciousness is no longer one between two purely opposite poles. The movement from matter to Spirit and from Spirit to matter can thus be described as a mediated interactional and mutual transformational process.

The information world fills the conceptual vacancy between material and Spiritual relationships "after God withdrew", but this is not achieved by introducing a mysterious objective spirit, but by an objective informational (non-material, non-energy) world derived from the activities of the objective material world itself.

Ontology and epistemology cannot be separated from the other fields of philosophy, and all areas of philosophy must take the ontology of philosophy as their foundation. The rejection or suspension of ontology of philosophy in Western contemporary philosophy suggests the idea that epistemology can construct itself independently of philosophical ontology. However, this kind of argument is essentially based on an ontology of philosophy that is limited to a simplistic opposition between and absolute separation of matter and Spirit. Unable to find the intermediary link between the Spiritual and material, contemporary Western philosophy had to retreat inward, to seek the explanation of consciousness in the internal processes of consciousness itself, as proposed by phenomenological doctrine.

\section{The Complex Characteristics of Multi-dimensional and Multi-polar Cognitive Activity}

The creation of an informational ontological doctrine provides a unified foundation for change in all other areas of philosophy, especially, for the transformation of epistemology. It is therefore necessary to establish an appropriate new informational epistemological doctrine.

Based on informational epistemological investigation, human cognitive activity involves the complex emergence of multi-dimensional and multi-polar features, novel and innovative. As a complex integrated construction, consciousness generates itself from inside and outside. It is all of the following at the same time: subjectively presented and potentially required; subjectively active and objectively passive; natural and individual; individual and social; directly presented and indirectly intermediated; current and historical; physical, psychological and behavioral; conscious, unconscious and subconscious.

In the philosophy of information I created, I proposed an "Informational Intermediary Theory of Epistemology" [6]. That theory of multi-intermediary constructions and virtual activities explains the general mechanisms and processes of human cognitive activities. There are four major types of intermediary in this theory: the objective informational field; the subject's own neuro-physiological structure; the subject's previously constructed cognitive structure; and the material means of subject cognition (tools, instruments). In addition, the complexity of human knowledge lies not only in its multiintermediary construction and the virtual nature of conscious activities, but also in its 1) historical 
character as a process of natural evolution; 2) its social generation. Human knowledge is constituted not only by the natural history and social history of the evolutionary origin and construction of a human being's physiological structure and the subject's genetically determined cognitive construction. It also includes the natural, social and cultural information environment and the generative and productive history of material tools that supplement the capacities of humans for social action.

So it seems that ontology and epistemology, as well as other areas of philosophy cannot be fragmented, and all other areas of philosophy must be based on a philosophical ontology.

\section{The Highest Paradigm and the Fundamental Informational Turn of Philosophy}

Western philosophy has defined two "turns" in its development, namely the two turns from ontology to epistemology and then to linguistics. Some scholars also add a phenomenological turn and theories of existence, and philosophies of value, practice and body as constituting major turns. However, there are no natural, general criteria provided for these so-called turning theories; their only claim to be called turns of philosophy refers to the changes in the main corresponding groups of philosophical problems.

In fact, the innovation of philosophy does not simply lie in the conversion of its groups of problems or the related disciplines, but in a new discourse on the domains, ideas, and contents of its inherent basic theory. In the study of philosophy, ontology, epistemology, methodology, language theory, practice theory, value theory, existence theory should be unified. So far all philosophical theories, all the interpretative theories of schools of philosophy are rooted in the prior understanding of general existence field and of the relation of human and object. These theories focus mainly on the relationships between matter and Spirit, subject and object as discussed above. The differences between various philosophical theories and schools of philosophy lies solely in the rejection or suspension of some aspects of these two kinds of relations, or more or less emphasis on the leading role of one opposite aspect $v s$. the other in the two kinds of relations. Some more extreme theories give a status of absolute supremacy to some factors or modes of the Spirit or object, thus even more absolute, partial and simplistic characterizations [7].

Traditional philosophy insists on the duality of matter and Sprit, considering that all things and phenomena in the world can be categorized into two major areas, namely the material and the Spiritual. This is an article of faith of traditional philosophy I have summed up as: existence $=$ matter + Spirit. Such a segmentation of the field of existence is the most basic ontological principle in traditional philosophy. From this ontological derives materialism or idealism depending on the interpretation between of the relation between matter and Spirit.

For me, philosophical ontology is a hierarchical paradigm. The method of segmentation of the realm of existence (extant domain) is the highest paradigm. The interpretation of the relationship between the different fields of existence is a secondary paradigm because only after determining the different fields can we study the relationship among them. If the general paradigm of traditional philosophy, "existence $=$ matter + Spirit" is its highest paradigm, then traditional materialism and idealism are not the highest paradigms of traditional philosophy, but can only be second level theoretical paradigms. If the segmentation mode of the field of existence field does not change but involves just a different interpretation of the relationship of matter and Spirit, then it cannot constitute a fundamental philosophical revolution. This is why the bases of a fundamental philosophical revolution in the development of human philosophy, in its true sense have never so far been realized. In the few 
philosophical turns of which Western scholars have conceived, because there are no transformations of the segmentation of existence field at the highest philosophical level of paradigm, these so-called philosophical turns lack fundamental significance.

\section{Conclusions}

The impact of computer science and information technology as such on knowledge is unquestionable and requires no additional comment here. My paper has been directed at a deeper philosophical level which, in contrast, has received little attention in the literature. It deals directly with its fundamental informational turn [8].

The philosophy of information, with the segmentation method of the field of existence as its highest paradigm, transforms the general article of faith that "existence $=$ matter + Spirit" in traditional philosophy into "existence = matter + information", and then re-interprets the essence of Spiritual activities in the sense of prior information activities. The discovery of an informational world provides the opportunity for a new, complex view of the constitution of the field of existence and the process of human cognition, breaking the traditional duality between matter and Spirit, and of subject and object as polar opposites. This constitutes a new, significant and fundamental change in philosophical ontology, epistemology, evolutionary theory, methodology, the philosophy of language, practice philosophy, value philosophy and theories of human nature and existence, production and society. Thus, the birth of the modern philosophy of information leads to the first truly fundamental turn of human philosophy [9].

\section{Acknowledgments}

This paper was translated from Chinese by Jian Wang and the translation revision by Joseph E. Brenner. Many thanks to both of them.

\section{Conflicts of Interest}

The author declares no conflict of interest.

\section{References}

1. Wu, K. The Development of Philosophy and its Fundamental Turn. J. Renmin Univ. Chin. 2014, 28, 72-78. (In Chinese)

2. Morin, E. La Méthode Tome 1: La nature de lature; Wu, H., Feng, X., Translators; Peking University Press: Beijing, China, 2002. (In Chinese)

3. Wu, K. On the relationship of science and philosophy. Sci. Technol. Dialect. 2004, 1, 1-3. (In Chinese)

4. Wu, K. The complex characteristics of the multidimensional "emergence" of human knowledgeA Critique of the one-dimensional, simplistic features of Husserl's phenomenological reduction theory. Hebei Acad. J. 2014, 4, 25-30. (In Chinese)

5. Husserl, E. Ideen zu einer reinen Phänomenologie und phänomenologischen Philosophie. Erstes Buch: Allgemeine Einführung in die reine Phänomenologie; Li, Y., Translator; The Commercial Press: Beijing, China, 2009; pp. 100-102, 156-159. (In Chinese) 
6. Wu, K. On the Informational Intermediary Theory of Philosophical Epistemology. Lanzhou Acad. J. 1984, 5, 57-63. (In Chinese)

7. Wu, K. Cognition: Informational Constructional Activity in Multi-intermediaries. J. Changsha Univ. Sci. Technol. (Soc. Sci.) 1989, 3, 17-22. (In Chinese)

8. $\mathrm{Wu}, \mathrm{K}$. The basic problem of philosophy and its fundamental turn. Hebei Acad. J. 2011, 4, 11-21. (In Chinese)

9. Wu, K. The Segmentation of the Field of Existence and the "Whole New Revolutionary" Significance of the Philosophy of Information. J. Humanitiess 2013, 5, 1-6. (In Chinese)

(C) 2015 by the authors; licensee MDPI, Basel, Switzerland. This article is an open access article distributed under the terms and conditions of the Creative Commons Attribution license (http://creativecommons.org/licenses/by/4.0/). 